\title{
Two-body wear rate of CAD/CAM resin blocks and their enamel antagonists
}

Stawarczyk, Bogna ; Özcan, Mutlu ; Trottmann, Albert ; Schmutz, Felix ; Roos, Malgorzata ; Hämmerle, Christoph

\begin{abstract}
STATEMENT OF PROBLEM: Computer-aided design and computer-aided manufacturing (CAD/CAM) resins exhibit good mechanical properties and can be used as long-term restorations. The wear rate of such resins and their enamel antagonists is unknown. PURPOSE: The purpose of this study was to test and compare the 2-body wear rate of CAD/CAM resin blocks. MATERIAL AND METHODS: Wear specimens $(\mathrm{N}=42, \mathrm{n}=6)$ were made from 5 CAD/CAM resins: ZENO PMMA (ZP), artBloc Temp (AT), Telio CAD (TC), Blanc High-class (HC), CAD-Temp (CT); 1 manually polymerized resin: Integral esthetic press (negative control group, IEP); and 1 glass-ceramic: VITA Mark II (positive control group, VM2). The specimens for the wear resistance were aged in a thermomechanical loading machine $\left(49 \mathrm{~N}, 1.67 \mathrm{~Hz}, 5 / 50^{\circ} \mathrm{C}\right)$ with human enamel antagonists. The material loss of all specimens before, during, and after aging was evaluated with a 3DS profilometer. The measured material loss data of all tested groups were statistically evaluated with linear mixed model analysis $(a=.05)$. RESULTS: Manually polymerized resin showed significantly higher material wear $(\mathrm{P}<.001)$ than all other tested groups. Glass-ceramic showed significantly lower wear values $(\mathrm{P}<.001)$ than $\mathrm{CAD} / \mathrm{CAM}$ resins $\mathrm{ZP}, \mathrm{AT}, \mathrm{HC}, \mathrm{CT}$, and IES. $\mathrm{CAD} / \mathrm{CAM}$ resin TC was not significantly different from the positive control group. Glass-ceramic showed the highest enamel wear values $(\mathrm{P}<.001)$ of all tested resins. No differences were found in the enamel wear among all resins. The glass-ceramic group showed damage in the form of cracks on the worn enamel surface in $50 \%$ of specimens. CONCLUSIONS: CAD/CAM resins showed lower wear rates than those conventionally polymerized. Only one CAD/CAM resin, TC, presented material wear values comparable with glass-ceramic. The tested glassceramic developed cracks in the enamel antagonist and showed the highest enamel wear values of all other tested groups.
\end{abstract}

DOI: https://doi.org/10.1016/S0022-3913(13)60309-1

Posted at the Zurich Open Repository and Archive, University of Zurich

ZORA URL: https://doi.org/10.5167/uzh-80036

Journal Article

Accepted Version

Originally published at:

Stawarczyk, Bogna; Ȯzcan, Mutlu; Trottmann, Albert; Schmutz, Felix; Roos, Malgorzata; Hämmerle, Christoph (2013). Two-body wear rate of CAD/CAM resin blocks and their enamel antagonists. Journal of Prosthetic Dentistry, 109(5):325-332.

DOI: https://doi.org/10.1016/S0022-3913(13)60309-1 
Two-body wear rate of CAD/CAM resin blocks and their enamel antagonists

Bogna Stawarczyk, MSc, Dipl Ing, ${ }^{a}$ Mutlu Özcan, Prof Dr med dent, PhD, ${ }^{\mathrm{b}}$ Albert

Trottmann, ${ }^{\mathrm{c}}$ Felix Schmutz, ${ }^{\mathrm{d}}$ Malgorzata Roos, PhD, ${ }^{\mathrm{e}}$ and Christoph Hämmerle, Prof, Dr med $\operatorname{dent}^{\mathrm{f}}$

University of Zurich, Zurich, Switzerland; Ludwig-Maximilians University Munich, Munich Germany

${ }^{a}$ Research Fellow, Clinic of Fixed and Removable Prosthodontics and Dental Material Science, Center of Dental Medicine, University of Zurich, and Department of Prosthodontics, Ludwig-Maximilians University Munich.

${ }^{\mathrm{b}}$ Head of Dental Materials Unit, Clinic of Fixed and Removable Prosthodontics and Dental Material Science, Center of Dental Medicine, University of Zurich.

${ }^{c}$ Dental Technician, Clinic of Fixed and Removable Prosthodontics and Dental Material Science, Center of Dental Medicine, University of Zurich.

${ }^{\mathrm{d}}$ Dental Technician, Clinic of Preventive Dentistry, Periodontology and Cariology, Center of Dental Medicine, University of Zurich.

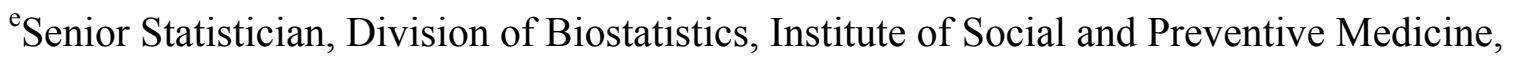
University of Zurich.

${ }^{\mathrm{f}}$ Chairman, Clinic of Fixed and Removable Prosthodontics and Dental Material Science, Center of Dental Medicine, University of Zurich 
Statement of problem. Computer-aided design and computer-aided manufacturing $(\mathrm{CAD} / \mathrm{CAM})$ resins exhibit good mechanical properties and can be used as long-term restorations. The wear rate of such resins and their enamel antagonists is unknown.

Purpose. This study tested and compared the 2-body wear rate of CAD/CAM resin blocks.

Material and methods. Wear specimens $(\mathrm{N}=42, \mathrm{n}=6)$ were made from $5 \mathrm{CAD} / \mathrm{CAM}$ resins: ZENO PMMA (ZP), artBloc Temp (AT), Telio CAD (TC), Blanc High-class (HC), CADTemp (CT); 1 manually polymerized resin: Integral esthetic press (negative control group, IEP); and 1 glass-ceramic: VITA Mark II (positive control group, VM2). The specimens for the wear resistance were aged in a thermomechanical loading machine $(49 \mathrm{~N}, 1.67 \mathrm{~Hz}$, $5 / 50^{\circ} \mathrm{C}$ ) with human enamel antagonists. The material loss of all specimens before, during, and after aging was evaluated by using a 3DS profilometer. The measured material loss data of all tested groups were statistically evaluated with linear mixed model analysis $(P<.05)$. Results. Manually polymerized resin showed significantly higher material wear $(P<.001)$ than all tested groups. Glass-ceramic showed significantly lower wear values $(P<.001)$ than CAD/CAM resins ZP, AT, HC, CT and IES. CAD/CAM resin TC was not significantly different from the positive control group. Glass-ceramic showed the highest enamel wear values $(\mathrm{P}<.001)$ of all tested resins. No differences were found in the enamel wear among all resins. The glass-ceramic group showed damage in the form of cracks on the worn enamel surface in $50 \%$ of specimens.

Conclusion. CAD/CAM resins showed lower wear rates than those conventionally polymerized. Only one CAD/CAM resin, TC, presented material wear values comparable with glass-ceramic. The tested glass-ceramic developed cracks in the enamel antagonist and showed the highest enamel wear values of all other tested groups.

\section{CLINICAL IMPLICATION}


CAD/CAM resins with lower wear than conventionally polymerized resins may be an appropriate choice for long-term use because they showed lower wear on enamel antagonists than glass-ceramic.

\section{INTRODUCTION}

Computer-aided design and computer-aided manufacturing (CAD/CAM) technology allows milling of different materials for dental applications. As an alternative to ceramics, $\mathrm{CAD} / \mathrm{CAM}$ polymers have been recently introduced for dental restorations, which can be processed more rapidly and at a lower cost. ${ }^{1}$ The resin CAD/CAM blocks are polymerized at high temperature and pressure under controlled conditions, resulting in consistent chemical and mechanical properties and higher flexural resistance than manually polymerized blocks. ${ }^{1-}$ ${ }^{4}$ In general, because manually polymerized resins show lower fracture resistance, they are only indicated for interim fixed dental prosthesis (FDPs). ${ }^{1-3}$ After 3 months of water storage at $37^{\circ} \mathrm{C}$ and 5000 thermal cycles, CAD/CAM resin 3-unit FDPs showed significantly higher fracture load than those manually polymerized. ${ }^{1}$ Another study tested the fracture load of 3 unit polymeric FDPs after 1.2 million masticatory cycles and observed higher and unaffected values by aging compared to manually polymerized resins and glass-ceramic FDPs. ${ }^{4}$ Therefore, polymeric CAD/CAM resins can be considered for long-term restorations and replace the indication for glass-ceramics for some patients. Furthermore, it was reported that polymeric $\mathrm{CAD} / \mathrm{CAM}$ resins exhibited similar color stability to glass-ceramic. ${ }^{5}$ The mechanical properties, such as flexural strength of glass-ceramic, ${ }^{6}$ are comparable to resins, ${ }^{7}$ but the hardness values of glass-ceramic ${ }^{8}$ are higher than those of resins. ${ }^{7}$ An advantage of all resin-based materials is their plastic deformability, which could prevent the spontaneous fracture of the restoration.

One of the important properties of dental materials is their wear resistance. Wear rate 
is defined as the loss of restorative material and/or its antagonist. The wear results because of mechanical contact in a solid or liquid body, or impact of chemical or mechanical reactions. ${ }^{2}$ The physical properties of enamel, ${ }^{9,10}$ parafunctional habits, eating habits, and the antagonist material have been reported to influence clinical wear. ${ }^{10-17}$ The authors identified no information to date on the wear of polymeric CAD/CAM resins.

In vitro wear tests have been performed using different devices such as the ACTA, Zurich, Alabama, Freiburg, Minnesota, OHSU, or Newcastle wear simulators. ${ }^{13}$ These test methods differ in the design, antagonist material, test medium, force application, and mobility of specimens. ${ }^{13,18,19}$ The Zurich wear test method used human enamel antagonists, possibly making the test more clinically relevant. ${ }^{13}$

The objective of this study was to determine the 2-body wear rate of industrially polymerized $\mathrm{CAD} / \mathrm{CAM}$ resins and compare this to manually polymerized resin and glassceramic. The study tested the null hypotheses that 1) the wear of CAD/CAM resins would be similar to manually polymerized resin, 2) the wear of CAD/CAM resins would be similar to glass-ceramic, and 3) the wear of antagonists of all tested groups would be similar.

\section{MATERIAL AND METHODS}

This study investigated the 2-body wear of 5 CAD/CAM resins: ZENO PMMA (ZP), artBlock Temp (AT), Telio CAD (TC), Blanc High-class (HC), CAD-Temp, 1 manually polymerized resin: Integral esthetic press (negative control group, IEP), and 1 glass-ceramic VITA MARK II (positive control group, VM2) and their enamel antagonists by using the Zurich wear simulation (ISO/TS 14569-2). ${ }^{13}$ The experimental groups are listed in Table I. For wear resistance testing, each test group included 6 specimens. The sample size was based on similar previous studies, which showed significant differences with a similar sample size. ${ }^{20,21}$ No a priori power analysis was performed. 
All CAD/CAM resins and glass-ceramic blocks were cut to a thickness of $2 \mathrm{~mm}$ with a low-speed diamond saw (Well 3241; Well Diamond Wire Saws Inc, Mannheim, Germany). The specimens were embedded in the center of circular stainless steel molds (inside diameter: $15 \mathrm{~mm}$ ) with an autopolymerizing acrylic resin (DuraLay; Reliance Dental Mfg. Co, Worth, Ill). The manually polymerized IEP resin was directly poured into a stainless steel mold and polymerized according to the manufacturer's instruction in a pressure pot $(30 \mathrm{~min}, 45 \mathrm{~min}$, 0.25 MPa, Ivoclar Vivadent, Schaan, Liechtenstein). Subsequently, all specimens were polished with SiC paper P400, P12000, and P2400 (LaboPol-21; Struers, Ballerup, Denmark).

The specimens were aged in a custom-made mastication simulator (University of Zurich). The simulator was computer-controlled, exerting a maximum occlusal load of $49 \mathrm{~N}$ at $1.67 \mathrm{~Hz}$. Thermal stresses varied between $5^{\circ} \mathrm{C}$ to $50^{\circ} \mathrm{C}$ every 120 seconds. The mesiobuccal cusps of maxillary human molars fixed in amalgam (Dispersalloy; Dentsply; Konstanz, Germany) were used as the antagonists. The tips of the cusps were adjusted to a spherical shape. The track of the enamel across the specimen surface was $2 \mathrm{~mm}$. Figure 1 demonstrates the fixed specimens in the mastication simulator. The abraded surfaces were loaded intermittently. The protocol used for the mastication simulation was similar to previous studies. $^{20,21}$ The vertical material loss $(\mu \mathrm{m})$ from the specimens and their enamel antagonists was analyzed with a custom made 3DS profilometer (University of Zurich). Measurements were made before aging (initial) and after 120 000, 240 000, 640 000, and 1 200000 masticatory cycles. ${ }^{13}$ The profiles with congruent points were overlapped, and the initial measurements were subtracted from later measurements. Subsequently, the material loss $(\mu \mathrm{m})$ from the specimens and their enamel antagonists was calculated with the 3DS software (University of Zurich).

Additionally the specimens were analyzed with scanning electron microscopy (SEM) 
(Carl Zeiss Supra 50 VP FESEM; Carl Zeiss, Oberkochen, Germany) after the wear tests.

Descriptive statistics for all tested groups in each aging time were calculated. Linear mixed models for 2 different baselines (positive and negative control group) were applied to investigate the influence of the number of masticatory cycles, the restorative materials/enamel, and the interaction between them. The measured material loss data were analyzed with the statistical software (SPSS, v19; SPSS Inc, Chicago, Ill). The results of statistical analyses with P-values less than .05 were interpreted as statistically significant.

\section{RESULTS}

The mean with standard division of the wear results of the materials and their enamel antagonists are presented in Figure 2. In general, the material $(P<.001)$ and the number of masticatory cycles $(\mathrm{P}<.01)$ had a significant effect on the wear (Table III and IV).

Material wear

The negative control group, IEP, showed significantly higher material wear $(P<.001)$ than all $\mathrm{CAD} / \mathrm{CAM}$ resins and the positive control group, VM2. Depending on masticatory cycles, the increase in the wear values was higher for the negative control group than for the CAD/CAM resins ZP, TC, HC, and the positive control group (Table III, Fig. 2).

The positive control group, VM2, showed significantly lower wear values $(P<.001)$ than the CAD/CAM resins ZP, AT, HC, CT, and the negative control group, IES. The CAD/CAM resin TC did not significantly differ from the positive control group. Depending on the aging time, the increase in the wear values was lower for the positive control group than for the CAD/CAM resins AT, CT, and the negative control group IEP (Table III, Fig. 2). Antagonist enamel wear

The positive control group VM2, glass-ceramic showed the highest enamel wear values $(P<.001)$ with the highest increase in material lost $(P<.001)$ compared to all 
CAD/CAM resins and the negative control group, IEP. No differences were found in the enamel wear between all resins (Table IV, Fig. 3 and 4).

An evaluation of the enamel antagonists with SEM showed damage in the form of cracks on the worn enamel surfaces of the glass-ceramic group. For both manually polymerized and CAD/CAM resins, no damage to the enamel antagonists was observed.

\section{DISCUSSION}

All industrially polymerized CAD/CAM resins showed lower vertical material loss, wear than manually polymerized resins. Therefore, the first null hypothesis of this study was rejected.

The second null hypothesis tested was whether the wear of CAD/CAM resins would be similar to glass-ceramic. Four $\mathrm{CAD} / \mathrm{CAM}$ resins showed higher material wear values compared to glass-ceramic. Only one CAD/CAM resin, TC, showed similar wear to glassceramic. Therefore, this hypothesis could be partially rejected. TC is a polymethylmethacrylate (PMMA) resin without organic or inorganic filler. In general, no correlation was found between the tested $\mathrm{CAD} / \mathrm{CAM}$ resins and their composition. Therefore, it is possible that the press and polymerization parameters of the $\mathrm{CAD} / \mathrm{CAM}$ resins have a significant impact of the wear rate.

The third null hypothesis was to test whether the wear of the antagonists of all tested groups would be similar. The glass-ceramic showed significantly higher wear on the antagonists than on the resins. Therefore, the third null hypothesis was rejected. The hardness values of glass-ceramic compared to resins were higher. The hardness, and surface texture of the restoration surface are the most important criteria for lower wear rate. For higher mechanical properties, glass-ceramic is reinforced by using further ceramic particles. While the thermomechanical loading process the particles may be pulled out. Consequently, with 
the increase in the masticatory cycles during the aging process, the wear rate of the glassceramic increased. Therefore, the material surface was rough and increased the abrasion of the enamel antagonists. Additionally, the enamel antagonists showed damage in the form of cracks on the worn enamel surfaces of the specimens in the glass-ceramic group. For the resin groups, no damage of the enamel antagonists was observed. During aging in the chewing simulator, both surfaces (enamel antagonist and glass-ceramic/resin) were abraded by direct contact, and during the movement, the asperities must have been either fractured or deformed. If both surfaces are brittle, such as in the positive control group of enamel against glass-ceramic, fracture of the asperities does occur.

In all tested groups in this study, the wear standard deviation varied highly. The lack of homogeneity in the human enamel antagonists, in the thickness or geometry of the enamel layers, and in the storage conditions possibly affected the results. ${ }^{14}$ The variations in the morphologies of the human tooth affect the wear rate. ${ }^{13}$ However, the used of human enamel antagonists represents clinical situations.

Little or no correlation was found between in vitro and in vitro studies. ${ }^{14}$ This could be attributed to the magnitude of force and the frequency. ${ }^{10,15-17}$ In this study, thermal cycling with water also contributed to the aging of the specimens. ${ }^{14}$

As the measurements for each specimen were made before aging and after 4 additional masticatory cycles, the predictor MC can be considered to be a dimensional variable rather than a factor with 5 levels as visualized in Figures 2 and 3. In such a case, the multiple regression methodology applies, and the estimated regression coefficients, along with their $95 \%$ CIs, for each of the materials in a regression model can be used to assess whether the materials differ. The baseline can be set to be the positive or alternatively the negative control group. As the tested specimens were used repeatedly for all MC and the measurements from each specimen were correlated, the longitudinal data were considered for 
statistical analysis. Consequently, the linear mixed models with random intercept, which were adjusted for the correlated data, were applied in order to investigate the influence of the number of chewing cycles.

A limitation of this study was the choice of the control groups. For the positive control group, glass-ceramic was used; all other tested materials were filled or unfilled polymeric resins. This study compared different classes of materials with different wear mechanisms. Glass-ceramic is a brittle material, whereas the resins are ductile. The basic idea for this study was to test the wear properties of different CAD/CAM resins with the expectation that, in the future, glass-ceramic restorations may be replaced with resins. However, the currently available CAD/CAM resins exhibit higher wear values than glassceramic. Additional work is needed to improve the wear properties of resins. Another limitation was the fact that no a priori power analysis was performed to determine sample size.

One study investigated and compared different two- and/or three wear test devices such as ACTA (Academisch Centrum Tandheelkunde Amsterdam), Zurich (University of Zurich), Alabama (University of Alabama at Birmingham), MTS (Material Testing Systems), and OHSU (Oregon Health \& Science University) for direct resin composites. ${ }^{18}$ The measured wear resistance of the tested resin composites with the different wear test methods showed no comparable results as all methods follow different wear testing concepts.

However, in vitro studies for wear resistance tests show little correlation with clinical data ${ }^{19}$ but do present a comparative evaluation of different materials under standardized conditions. ${ }^{10}$ The results of this study require clinical verification.

\section{CONCLUSION}

Within the limitations of this study, the following conclusions can be drawn: CAD/CAM 
resins showed lower wear values than those manually polymerized. CAD/CAM resins showed higher wear values than glass-ceramic, with the exception of TC. Both manually polymerized and $\mathrm{CAD} / \mathrm{CAM}$ resins showed lower enamel antagonist wear values than glassceramic. Although in the glass-ceramic group 50\% of the specimens developed cracks in enamel, no such damage was observed in the resin groups. 


\section{REFERENCES}

1. Alt V, Hannig M, Wostmann B, Balkenhol M. Fracture strength of temporary fixed partial dentures: CAD/CAM versus directly fabricated restorations. Dent Mater 2011;27:339-47.

2. Balkenhol M, Mautner MC, Ferger P, Wostmann B. Mechanical properties of provisional crown and bridge materials: chemical-curing versus dual-curing systems. J Dent 2008;36:1520.

3. Goncu Basaran E, Ayna E, Vallittu PK, Lassila LV. Load-bearing capacity of handmade and computer-aided design--computer-aided manufacturing-fabricated three-unit fixed dental prostheses of particulate filler composite. Acta Odontol Scand 2011;69:144-50.

4. Stawarczyk B, Ender A, Trottmann A, Özcan M, Fischer J, Hämmerle CHF. Load-bearing capacity of CAD/CAM milled polymeric three-unit fixed dental prostheses: Effect of aging regimens. Clin Oral Investig 2012 [epub ahead of print]

5. Hooshmand T, Parvizi S, Keshvad A. Effect of surface acid etching on the biaxial flexural strength of two hot-pressed glass ceramics. J Prosthodont 2008;17:415-9.

6. Fischer J, Roeske S, Stawarczyk B, Hammerle CH. Investigations in the correlation between Martens hardness and flexural strength of composite resin restorative materials. Dent Mater J 2010;29:188-92.

7. Chaysuwan D, Sirinukunwattana K, Kanchanatawewat K, Heness G, Yamashita K. Machinable glass-ceramics forming as a restorative dental material. Dent Mater J 2011;30:358-67.

8. ISO14569-2: Dental materials - Guidance on testing of wear - Part 2: Wear by two/ or three body contact. Geneva, Switzerland: International Organization for Standardization. 2001. http://www.iso.org/iso/store.htm

9. Rosentritt M, Behr M, Gebhard R, Handel G. Influence of stress simulation parameters on the fracture strength of all-ceramic fixed-partial dentures. Dent Mater 2006;22:176-82. 
10. Rosentritt M, Siavikis G, Behr M, Kolbeck C, Handel G. Approach for valuating the significance of laboratory simulation. J Dent 2008;36:1048-53.

11. Rosentritt M, Behr M, van der Zel JM, Feilzer AJ. Approach for valuating the influence of laboratory simulation. Dent Mater 2009;25:348-52.

12. Hahnel S, Behr M, Handel G, Rosentritt M. Two-body wear of artificial acrylic and composite resin teeth in relation to antagonist material. J Prosthet Dent 2009;101:269-78. 13. Preis V, Behr M, Kolbeck C, Hahnel S, Handel G, Rosentritt M. Wear performance of substructure ceramics and veneering porcelains. Dent Mater 2011;27:796-804.

14. Johansson A, Haraldson T, Omar R, Kiliaridis S, Carlsson GE. An investigation of some factors associated with occlusal tooth wear in a selected high-wear sample. Scand J Dent Res 1993;101:407-15.

15. Johansson A, Kiliaridis S, Haraldson T, Omar R, Carlsson GE. Covariation of some factors associated with occlusal tooth wear in a selected high-wear sample. Scand J Dent Res $1993 ; 101: 398-406$.

16. Mair LH, Stolarski TA, Vowles RW, Lloyd CH. Wear: mechanisms, manifestations and measurement. Report of a workshop. J Dent 1996;24:141-8.

17. Kim SK, Kim KN, Chang IT, Heo SJ. A study of the effects of chewing patterns on occlusal wear. J Oral Rehabil 2001;28:1048-55.

18. Heintze SD. How to qualify and validate wear simulation devices and methods. Dent Mater 2006;22:712-34.

19. Lambrechts P, Debels E, Van Landuyt K, Peumans M, Van Meerbeek. How to simulate wear? Overview of existing methods. Dent Mater 2006;22:693-701.

20. Stawarczyk B, Egli R, Roos M, Özcan M, Hämmerle CHF. The impact of in vitro aging on the mechanical and optical properties of indirect veneering composite resins. J Prosthet Dent 2011;106:386-98. 
21. Stawarczyk B, Özcan M, Schmutz F, Trottmann A, Roos M, Hämmerle CHF. Two-body wear of monolithic, veneered and glazed zirconia and their corresponding enamel antagonists. Acta Odont Scand 2012; early online, 1-11.

Corresponding author:

Dr Bogna Stawarczyk

Department of Prostodontics

Ludwig-Maximilians University Munich

Goethestrasse 70,

80336 Munich

GERMANY

Fax: +49-89-5160-9573

E-mail: bogna.stawarczyk@med.uni-muenchen.de

Acknowledgments

The authors thank Mrs Jacqueline Hofmann, Center of Dental Medicine, University of Zurich, for performing the scanning electron microscopy, and to Wieland Dental + Technik, Merz Dental, Ivoclar Vivadent and Vita Zahnfabrik for material support. 
Table I. Test groups, abbreviations, brands, batch numbers, manufacturers and composition of tested materials

\begin{tabular}{|c|c|c|c|c|}
\hline Test group & Abbreviation & $\begin{array}{l}\text { Batch } \\
\text { Number }\end{array}$ & Manufacturer & Composition \\
\hline $\begin{array}{l}\text { ZENO } \\
\text { PMMA }\end{array}$ & $\mathrm{ZP}$ & 0483 & $\begin{array}{l}\text { Wieland Dental }+ \\
\text { Technik, } \\
\text { Pforzheim, } \\
\text { Germany }\end{array}$ & PMMA-based \\
\hline $\begin{array}{l}\text { artBlock } \\
\text { Temp }\end{array}$ & AT & 13708 & $\begin{array}{l}\text { Merz Dental, } \\
\text { Lütjenburg, } \\
\text { Germany }\end{array}$ & $\begin{array}{l}\text { PMMA, OMP=organic } \\
\text { modified polymer network }\end{array}$ \\
\hline $\begin{array}{l}\text { Telio } \\
\text { CAD }\end{array}$ & TC & MM1068 & $\begin{array}{l}\text { Ivoclar Vivadent, } \\
\text { Schaan, } \\
\text { Liechtenstein }\end{array}$ & 99.5\% PMMA Polymer \\
\hline $\begin{array}{l}\text { Blanc } \\
\text { High-class }\end{array}$ & $\mathrm{HC}$ & 2007000908 & $\begin{array}{l}\text { Creamed, } \\
\text { Marburg, Germany }\end{array}$ & $\begin{array}{l}\text { BODMA, Bis-GMA, } \\
\text { UDMA, Strontium } \\
\text { aluminum borosilicate glass } \\
70.1 \% \text {, nanofilled }\end{array}$ \\
\hline $\begin{array}{l}\text { CAD- } \\
\text { Temp }\end{array}$ & $\mathrm{CT}$ & 19180 & $\begin{array}{l}\text { Vita Zahnfabrik, } \\
\text { Bad Säckingen, } \\
\text { Germany }\end{array}$ & $\begin{array}{l}\text { Acrylic polymer with } 14 \% \\
\text { microfiller. } \mathrm{MRP}= \\
\text { microfilled reinforced } \\
\text { polyacrylate }\end{array}$ \\
\hline $\begin{array}{l}\text { Integral } \\
\text { esthetic } \\
\text { press }\end{array}$ & IEP & $\begin{array}{l}1 / 4106 \\
55007\end{array}$ & Merz Dental & $\begin{array}{l}\text { MMA, dimethacrylate, } \\
\text { barbuturic acid catalyst } \\
\text { system, PMMA, organic }\end{array}$ \\
\hline
\end{tabular}




\begin{tabular}{|l|l|l|l|l|}
\hline & & & & and inorganic pigments \\
\hline Vita Mark & VM2 & 16341 & Vita Zahnfabrik & SiO-based glass-ceramic \\
\hline
\end{tabular}


Table II. Estimates of regression coefficients for wear of restorative materials with positive (VM2) and negative group (IEP) as baseline (linear mixed model analysis)

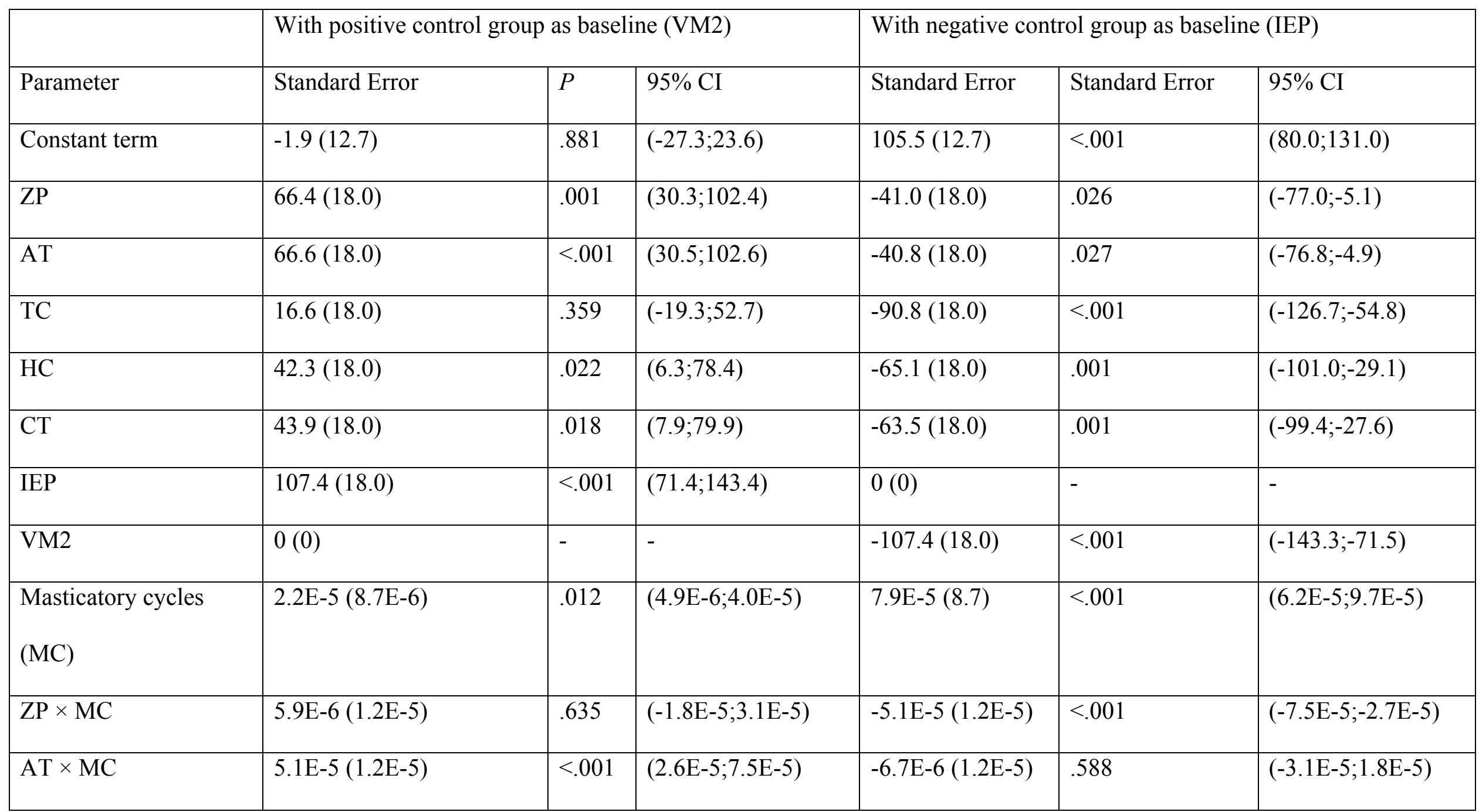




\begin{tabular}{|l|l|l|l|l|l|l|}
\hline $\mathrm{TC} \times \mathrm{MC}$ & $-2.7 \mathrm{E}-6(1.2 \mathrm{E}-5)$ & .830 & $(-2.7 \mathrm{E}-5 ; 2.2 \mathrm{E}-5)$ & $-6.0 \mathrm{E}-5(1.2 \mathrm{E}-5)$ & $<.001$ & $(-8.4 \mathrm{E}-5 ;-3.6 \mathrm{E}-5)$ \\
\hline $\mathrm{HC} \times \mathrm{MC}$ & $1.2 \mathrm{E}-5(1.2 \mathrm{E}-5)$ & .337 & $(-1.2 \mathrm{E}-5 ; 3.7 \mathrm{E}-5)$ & $-4.5 \mathrm{E}-5(1.2 \mathrm{E}-5)$ & $<.001$ & $(-6.9 \mathrm{E}-5 ;-2.1 \mathrm{E}-5)$ \\
\hline $\mathrm{CT} \times \mathrm{MC}$ & $3.7 \mathrm{E}-5(1.2 \mathrm{E}-5)$ & .003 & $(1.2 \mathrm{E}-5 ; 6.2 \mathrm{E}-5)$ & $-2.0 \mathrm{E}-5(1.2 \mathrm{E}-5)$ & .105 & $(-4.4 \mathrm{E}-5 ; 4.3 \mathrm{E}-5)$ \\
\hline IEP $\times \mathrm{MC}$ & $5.7 \mathrm{E}-5(1.2 \mathrm{E}-5)$ & $<.001$ & $(3.2 \mathrm{E}-5 ; 8.2 \mathrm{E}-5)$ & $0(0)$ & - & - \\
\hline $\mathrm{VM} 2 \times \mathrm{MC}$ & $0(0)$ & - & - & $-5.7 \mathrm{E}-5(1.2 \mathrm{E}-5)$ & $<.001$ & $(-8.1 \mathrm{E}-5 ;-3.3 \mathrm{E}-5)$ \\
\hline
\end{tabular}


Table III. Estimates of regression coefficients for wear of enamel antagonist with positive (VM2) and negative group (IEP) as baseline (linear mixed model analysis)

\begin{tabular}{|c|c|c|c|c|c|c|}
\hline \multirow[b]{2}{*}{ Parameter } & \multicolumn{3}{|c|}{ With Positive Control Group As Baseline (VM2) } & \multicolumn{3}{|c|}{ With Negative Control Group As Baseline (IEP) } \\
\hline & Standard Error & $P$ & $95 \% \mathrm{CI}$ & Standard Error & $P$ & $95 \% \mathrm{CI}$ \\
\hline Constant term & $27.8(3.3)$ & $<.001$ & $(21.1 ; 34.4)$ & $7.5(3.3)$ & .026 & $(0.9 ; 14.2)$ \\
\hline $\mathrm{ZP}$ & $-25.0(4.6)$ & $<.001$ & $(-34.2 ;-15.7)$ & $-4.8(4.6)$ & .311 & $(-14.0 ; 4.6)$ \\
\hline AT & $-22.0(4.6)$ & $<.001$ & $(-31.4 ;-12.8)$ & $-1.8(4.6)$ & .697 & $(-11.1 ; 7.6)$ \\
\hline $\mathrm{TC}$ & $-23.7(4.6)$ & $<.001$ & $(-33.1 ;-14.5)$ & $-3.5(4.6)$ & .45 & $(-12.8 ; 5.8)$ \\
\hline $\mathrm{HC}$ & $-21.7(4.6)$ & $<.001$ & $(-31.0 ;-12.4)$ & $-1.5(4.6)$ & .753 & $(-10.7 ; 7.9)$ \\
\hline CT & $-19.4(4.6)$ & $<.001$ & $(-28.7 ;-10.1)$ & $0.8(4.6)$ & .867 & $(-8.5 ; 10.2)$ \\
\hline IEP & $-20.2(4.6)$ & $<.001$ & $(-29.5 ;-10.9)$ & $0(0)$ & - & - \\
\hline VM2 & $0(0)$ & - & - & $20.2(4.6)$ & $<.001$ & $(10.8 ; 29.6)$ \\
\hline Masticatory cycles (MC) & $3.4 \mathrm{E}-5(1.9 \mathrm{E}-6)$ & $<.001$ & $(3.0 \mathrm{E}-5 ; 3.8 \mathrm{E}-5)$ & $8.0(1.9)$ & $<.001$ & (4.4E-6;1.2E-5) \\
\hline $\mathrm{ZP} \times \mathrm{MC}$ & $-3.0(2.8 \mathrm{E}-6)$ & $<.001$ & $(-3.5 \mathrm{E}-5 ;-2.5 \mathrm{E}-5)$ & $-3.7 \mathrm{E}-6(2.8 \mathrm{E}-6)$ & .173 & $(-9.2 \mathrm{E}-6 ; 1.7 \mathrm{E}-6)$ \\
\hline $\mathrm{AT} \times \mathrm{MC}$ & $-2.9(2.8 \mathrm{E}-6)$ & $<.001$ & $(-3.4 \mathrm{E}-5 ;-2.4 \mathrm{E}-5)$ & $-2.6 \mathrm{E}-6(2.8 \mathrm{E}-6)$ & .347 & $(-8.0 \mathrm{E}-6 ; 2.9 \mathrm{E}-6)$ \\
\hline $\mathrm{TC} \times \mathrm{MC}$ & $-2.8(2.8 \mathrm{E}-6)$ & $<.001$ & $(-3.3 \mathrm{E}-5 ;-2.3 \mathrm{E}-5)$ & $-1.5 \mathrm{E}-6(2.8 \mathrm{E}-6)$ & .599 & $(-6.9 \mathrm{E}-6 ; 4.0 \mathrm{E}-6)$ \\
\hline
\end{tabular}




\begin{tabular}{|l|l|l|l|l|l|l|}
\hline $\mathrm{HC} \times \mathrm{MC}$ & $-2.9(2.8 \mathrm{E}-6)$ & $<.001$ & $(-3.3 \mathrm{E}-5 ;-2.4 \mathrm{E}-5)$ & $-2.6 \mathrm{E}-6(2.8 \mathrm{E}-6)$ & .355 & $(-8.0 \mathrm{E}-6 ; 2.9 \mathrm{E}-6)$ \\
\hline $\mathrm{CT} \times \mathrm{MC}$ & $-2.4(2.8 \mathrm{E}-6)$ & $<.001$ & $(-2.8 \mathrm{E}-5 ;-1.9 \mathrm{E}-5)$ & $1.9 \mathrm{E}-6(2.8 \mathrm{E}-6)$ & .489 & $(-3.5 \mathrm{E}-6 ; 7.4 \mathrm{E}-6)$ \\
\hline $\mathrm{IEP} \times \mathrm{MC}$ & $-2.6(2.8 \mathrm{E}-6)$ & $<.001$ & $(-3.1 \mathrm{E}-5 ;-2.1 \mathrm{E}-5)$ & $0(0)$ & - & - \\
\hline $\mathrm{VM} 2 \times \mathrm{MC}$ & $0(0)$ & - & - & $2.6 \mathrm{E}-5(2.8 \mathrm{E}-6)$ & $<.001$ & $(2.0 \mathrm{E}-5 ; 3.2 \mathrm{E}-5)$ \\
\hline
\end{tabular}




\section{LEGENDS}

Fig. 1. Specimens fixed in mastication simulator.

Fig. 2. Wear $(\mu \mathrm{m})$ of all tested A, restorative materials. B, enamel antagonists after 120000 , 240000,640000 , and 1200000 masticatory cycles.

Fig. 3 Linear mixed model diagram of restorative materials wear.

Fig. 4. Linear mixed model diagram of enamel antagonist wear.

Fig. 5. Typical SEM images (magnification: $\times 250$ ) of abraded restorative materials after 1 200000 masticatory cycles. A, group ZP. B, group AT. C, group TC. D, group HC. E, group CT. F, group IE. G, group VM2 (control group). 